\title{
Do horror: a cena contemporânea
}

\section{Celso Favaretto}

\begin{abstract}
Resumo: Hoje a representaçáo do horror não mais decorre, como se acreditou, da multiplicação dos teatros da memória e da perda de eficácia dos dispositivos da representação, efetuados pelo enfraquecimento do símbólico, com a contribuição das vảrias tecnologias da comunicaçắo. Tal enfraquecimento resulta da potència das imagens que circulam, do excesso e da espetacularização que compóem o seu regime estético. Passados o tempo de circulaçẫo de teorias e as experiências de fechamento da representação, percebe-se que não temos ainda "uma linguagem que esteja à altura de traduzir o estado atual das coisas". Palavras-chave: representação do horror, vanguardas modernas, arte contemporànea.
\end{abstract}

\begin{abstract}
The representation of humor today does not result, as it was believed, from the memory theaters multiplication, neither from the efficiency loss of means of representation, taken effect by the waning of the symbolic, with the contribution of various communication technologies, Such waning results from the power of the images circulating, from the excess and spectacularization that make up the esthetic regime. After the time of circulating theories and experiences of closing the representation, it can be noted that we still don't have "a language which is worth translating the current state of things". Keywords: representation of horror, modern avant-garde, contemporaneous arh.
\end{abstract}


Das referências de Conrad e Eliot a Coppola - O coração das trevas, citado na epígrafe de Os homens ocos ("O senhor Kurtz, ele morreu") e em Apocalipse now -, aos acontecimentos históricos e na vida de todo dia; de Auschwitz ao Vietnam, das torres de Nova Iorque ao Iraque, das hecatombes naturais aos desastres aéreos, da miséria, das epidemias aos genocídios em Ruanda e outras mazelas que grassam nos diversos continentes, ressoa o grito terrificante: "O horror, o horror!"

A representação do horror e da morte, constantes na arte desde sempre, passou no século xx por uma rápida transformação: da crença na morte da representação à sua reaparição; e, inversamente, da representação da morte à efetivação das imagens da morte na realidade. Porque, cada vez com mais frequência e intensidade, vem ocorrendo alguma coisa semelhante ao que na psicanálise é designado como passagem ao ato: entre a representação e os atos impulsivos, violentos, agressivos e mortais parece não haver distância. A ausência do efeito de choque e do sentimento de estranheza parece derivar de uma espécie de naturalização da violência e da morte. Assim, o horror. Hoje, a representação do horror não mais decorre, como já se acreditou, da simples multiplicação dos teatros da memória e da perda de eficácia dos dispositivos da representação, efetuados pelo enfraquecimento do simbólico, inclusive com a contribuição das várias tecnologias da comunicação. Especificamente, tal enfraquecimento resulta da potência das imagens que circulam, do excesso e da espetacularização que compõem o seu regime estético. Atualmente, esta potência depende da aplicação, certeira ou equivocada, dos efeitos de presentificação; dos modos de experimentar as coisas em presença ou da tentativa de instaurar a presença como antídoto às da representação, às falsificações do real; ou ainda, como antídoto à própria crença de que o real pode ser representado. O horror de Conrad e de Coppola parece também atualizar o que diz Eliot em Quatro quartetos: "o gênero humano/ não pode suportar tanta realidade".

Passados, na arte e na filosofia da modernidade, o tempo de circulação de teorias e experiências de fechamento da representação, percebe-se que a questão agora é outra: não temos ainda "uma linguagem que esteja à altura de traduzir o estado atual das coisas", que corresponda "a situações completamente indeterminadas, aleatórias, flutuantes". O que temos "é a linguagem da representação, que é a linguagem do sujeito - o que, aliás, é bom, ela é simbólica, ambivalente". Ela não serve para falar daquilo que nos perturba - o horror -, pelo menos tal como ela aparece nos vários teatros da representação, artísticos ou culturais, sempre interessados em

1 Cf. BAUDRILLARD, Jean. Entrevista. Folha de S.Paulo, São Paulo, 23 dez. 1987. Ilustrada, p. A-37.

82 . FAVARETTO, Celso. Do horror: a cena contemporânea 
responder a exigências diversas de identificação dos espectadores ou dos protagonistas de uma realidade em cena. Pois "a linguagem que dá valor objetivo à representação é um processo de identificação e de sublimação que funciona no medo e se constitui como um véu, uma tela (écran) que nos separa e nos protege do fluxo caótico do devir" ${ }^{2} \mathrm{O}$ horror é, assim, o irrepresentável, o inominável. ${ }^{3}$

Talvez seja este o grande desafio colocado para todas as artes depois do grande trabalho das vanguardas, que levou ao fim as possibilidades da crítica da representação, com a destruição das convenções que presidiam à produção da ilusão. A recuperação da presença, agora entretanto uma espécie de aura transmutada, tem em vista repropor o sentido da representação. Depois da assepsia, ou da terapia, efetuada pelo trabalho das vanguardas, que pôs em causa a representação como sistema, linguagem e modo artístico produzidos nos tempos modernos - com o seu perspectivismo e experimentalismo científico, com o alargamento das fronteiras geográficas e culturais, com a invenção do espaço pictural, do espaço teatral, do espaço literário e da escala musical -, a presença e a pura materialidade da forma são reivindicadas como possibilidades de reencontro com uma realidade aquém ou além da simulação do real.

Livre do imperativo moderno, particularmente vanguardista, de propor a ruptura e buscar o novo, muita arte dita contemporânea vaga no indeterminado, tendo que definir, em cada caso, enquanto se inventa, as regras e as categorias que a singularizam e que propiciam a fruição e o julgamento. Desidealizada, esta arte exercita-se na tensão com os limites da modernidade, remetendo-se a um "sujeito operativo" e não mais a um "sujeito focal"4 como o herdado da Renascença. Não prometendo nenhuma experiência de completude, assim dificulta a articulação de uma crítica da cultura, portanto, a aposta na transformação da vida. Porque não propõe ideias suficientemente fortes para fundamentar práticas, vive de incertezas e surpresas, entre a inquietação e a indiferença, ansiando, talvez, por um preenchimento que dê conta da irrisão dos projetos modernos. ${ }^{5}$

Assim, essa arte, de um lado, vaga entre desejos de restauração de projetos e operações que outrora tiveram sentido, resgatando, como se diz, a possibilidade de

2 WARIN, François. La représentation de l'horreur. Marseille: Lycée St. Charles, nov. 2001, p. 5.

3 Cf. a análise de O coraçāo das trevas em: LIMA, Luiz Costa. O redemunho do horror: as margens do Ocidente. Sāo Paulo: Planeta, 2003, p. 212-27.

4 Cf. WARIN, François. La représentation de l'horreur, op. cit.

5 Cf. COELHO, Eduardo Prado. Para comer a sopa até o fim. Jornal do Brasil, Rio de Janeiro, 03 nov. 1991. Ideias/ Ensaios, p. 4. 
articulação entre criação e crítica. Ou então, por outro lado, dedica-se a recodificar, reiterar e eventuar. Aqui e ali surpresas acontecem: um tensionamento de signos da experiência, uma reinterpretação que vira um modo inédito de enunciar, uma reinscrição do simbólico onde só havia repetição, um nexo surpreendentemente de sensibilidade e pensamento que interferem no circuito da razão comunicativa, repropondo a arte com sentido de intervenção cultural. São estes lampejos, estes acontecimentos, que afirmam as potências do puro viver. Pois é disto que se trata hoje na arte: reinventar a arte de viver. Curiosamente, tudo aqui vem enunciado pela partícula re. Um re que significa elaboração: levantamento dos esquecimentos, dos recalques, das supressões promovidos pelos dispositivos vanguardistas e pelo projetualismo moderno. Trata-se, então, de indiciar com este re que agora estamos em pleno processo de elaboração, analisando os processos modernos, especialmente os de vanguarda. Talvez, uma tática para voos futuros.

Pois sabemos que o grande horror é a morte e que, lembrando Artaud, a vida é sempre a morte de alguém, ou de alguma coisa - podemos acrescentar. E sabemos também que a arte nos é dada para de alguma forma dar conta do fundo horrível das coisas, para que possamos suportar o incomensurável, o insuportável da existência contemporânea. Ora, para suportar esta condição é que inventamos as representações, a representação do insuportável, do horror. Por isso, embalde foram as estratégias e as operações da arte da modernidade: o fundo permanece, a ponto de não termos linguagem que dê conta de nossa realidade; assim, lançamos mão da linguagem da representação. Mas a experiência do horror põe em causa a distância que implica a representação. O que a modernidade fez muito bem, o seu grande feito, é preciso sempre lembrar, foi a reversão da noção e do modelo da representação no pensamento, na linguagem e nas artes.

A representação, como se sabe, está no centro das posições filosóficas no que diz respeito às relações entre o pensamento e a realidade. As noções de sujeito e de consciência aí estão para atestar o primado da representação: nas imagens que o homem faz de si em espelho, das personagens com que se institui socialmente e nas imagens que a sociedade dá de si mesma em espetáculo permanente. As imagens assim constituídas foram desde sempre a matriz das instituições, sistema de representação coletiva e, simultaneamente, modos suplementares de produção do sentido da existência, conjuração das potências invisíveis. Assim, a representação é a matriz de nossa identidade, cifrada nas imagens. Todo o drama contemporâneo, no pensamento e na arte, está na tentativa de lidar com esta velha doença ocidental, como diz Deleuze, a representação, de que um claro emblema é a chamada crise do 
sujeito, das dificuldades da afirmação de subjetividades, já que este fato não mais deriva das exigências daquela subjetividade inventadas na filosofia moderna, de Descartes a Kant, em que o real e o sujeito se recobrem. Conhecemos toda a discussão aí implicada, com as repercussões na arte, a ponto de Nietzsche, sintomaticamente, declarar que "temos a arte para não morrermos de verdade".

Então, onde estamos quando consideramos que a arte serve para aguçar nossa sensibilidade e reforçar nossa capacidade de suportar o incomensurável? ${ }^{6}$ Onde estamos, quando constatamos que "nenhuma ideia nos assegura a salvação, nenhuma ideia é portadora de uma verdade que salve, nenhuma ideia nos dispensa de sermos nós próprios a criarmos o nosso modelo e itinerário de salvação"? E ainda: que "nenhuma ideia é suficientemente forte para fundamentar uma prática, para funcionar como ciência rigorosa da práxis. Sem astros que nos guiem, sem uma ciência da navegação que apenas seja preciso aplicar, avançamos agora num mar de surpresas e incertezas". Contudo, "se não procurarmos ideias que salvem ou fundamentem, mas sim, a proliferação de teses, conceitos, redes, deslocações, sobreposições, derivas e invenções, deparamos com uma paisagem desconhecida que é preciso configurar e decifrar"?

Nesta paisagem desconhecida, que é preciso configurar - através dos signos que aparecem em toda parte, já que o essencial "está no instante da aparição das coisas"- ${ }^{8}$ há cenários que se delineiam. Por exemplo, aquele que se impõe no horizonte mais imediato da cultura: em sua instância predominante, a do mercado e a do lazer que, ao mesmo tempo que exaltam o vivido, as experiências mutáveis, múltiplas e simultâneas, neutralizam a distância, o recolhimento e abolem a mediação que a representação necessariamente introduz. ${ }^{9}$ Ou então, a crença absoluta na experiência, de que é possível um acesso imediato à realidade - que, é bom relembrar, é irrepresentável -, ou o reencontro com um eu, mítica fonte de unidade. Mas com que unidade sonhamos? Aquela, diz Lyotard, que acredita ser possível reorganizar os elementos da vida cotidiana numa unidade sociocultural? ${ }^{10}$ Aquela prometida pela restauração da unidade perdida agenciada pelos museus e teatros da memória? Ou a que apela para o mito do vivencial? Ou aquela que ante a confusão do espaço

6 LYOTARD, Jean-François. O pós-moderno. Trad. Ricardo Corrêa Barbosa. Rio de Janeiro: José Olympio, 1986, p. xvii.

7 COELHO, Eduardo Prado. Para comer a sopa até o fim, op. cit.

8 BAUDRILLARD, Jean. De um fragmento ao outro. Trad. João Guilherme de Freitas. São Paulo: Zouk, 2003, p. 31.

9 Cf. WARIN, François. La représentation de l'horreur, op. cit., p. 5-6.

10 Cf. LYOTARD, Jean-François. O pós-moderno explicado às crianças. Trad. Tereza Coelho. Lisboa: Dom Quixote, 1987, p. 15. 
público e do espaço privado quer dar consistência àquilo que agora são simples efeitos de uma suposta ordem objetiva, da lei? Referimo-nos, obviamente, às esperanças colocadas atualmente na recuperação da interioridade, da intimidade, da alteridade, da subjetividade. Mas o que querem dizer estas noções, para não serem entendidas como recaídas na idealidade, manifestação da carência de ideal e, simultaneamente, vulto de dispositivos de suplência do ideal?

A modalidade de manifestação artística e atividade cultural típica da sociedade do consumo é o evento, ele mesmo tornando-se o próprio acontecimento artístico, funcionando como elemento essencial da estetização da vida cotidiana processada pela cultura do consumo. Assim, na cena contemporânea, quando se pretendem identificar questões artísticas e práticas culturais renovadas, inclusive com poder de transgressão, ou alguma eficácia crítica, percebe-se uma grande dificuldade: a arte fundida à vida sob a modalidade do evento acaba por dissolver os signos numa categoria típica da arte dessublimada, da estetização generalizada da cultura das metrópoles, que é a categoria do "interessante". Esta tanto se afasta das categorias tradicionais, do belo, do maravilhoso, quanto das modernas, do novo e da ruptura." Ora, sabe-se que o que é interessante é indiferenciado. O evento, diz Lyotard, ${ }^{12}$ é exatamente uma maneira de exibição de objetos ou de situaçōes estetizadas. Nele o interesse estético desloca-se dos objetos, obras etc. para concentrar-se nos comportamentos dos participantes de um acontecimento cultural - participando, aliás, das mesmas categorias das instalações. Participar, entretanto, não tem a ver aqui com a categoria artística moderna que surge com a desestetização, com a abertura da obra de arte, implicando sempre um teor reflexivo.

Os trabalhos artísticos que funcionam segundo a modalidade do evento, embora pretendessem, inicialmente, interferir, até mesmo dialetizar, o meio de arte, isto é, o sistema artístico, convertem-se frequentemente em instâncias de comunicação. Dessa forma, perdem o valor crítico pretendido, qual seja: provocar um acontecimento localizado que, explorando a força do instante, daria lugar à exploração de signos de resistência, entendendo-se este trabalho como explicitação da angústia causada pela perda do próprio objeto da arte em virtude do aprisionamento dos objetos e do desejo pelo consumo. Assim, a estetização generalizada é simultaneamente

11 Cf. GALARD, Jean. Repères por l'élargissement de l'expérience esthétique. Diogène, 119. Paris: Gallimard, 1982, p. 94.

12 Cf. LYOTARD, Jean-François. Moralidades pós-modernas. Trad. Marina Appenzeller. Campinas: Papirus, 1996, (col. Travessia do Século), p. 29 e ss. 
fruto da desestetização moderna e perda do vigor de nexos e tensões dos dispositivos modernos, como a tensão entre o sensível e o racional, entre construtividade e vivência, por exemplo. Mas não seria possível pensar outra posição da experiência dos acontecimentos que não se submetesse a esta estética generalizada presa do consumo, ou seja, não seria possível pensar outra maneira de se entender a estetização do cotidiano, num espaço cultural em que as representações simbólicas foram afetadas até a raiz? Em suma: seria possível pensar em outra ordem do simbólico no nível dessa cultura dessublimada? Ou então: quais as possibilidades de reinstauração da simbolização e do espírito crítico na cultura do espetáculo?

Ao se recusarem as promessas redentoras da totalidade, da teleologia dos sistemas de pensamento, enfim dos sistemas de representação, a aposta que se tem de fazer é não se render à tentação de preencher o vazio que então se instala, colmatar o vazio, mas, o que é, repito, uma aposta, descobrir e trabalhar nos interstícios (na falha, na brecha) do vazio. Na linguagem, no pensamento e na arte, trata-se de assumir as coisas em sua singularidade e, ao mesmo tempo, em sua literalidade, na forma. Descobrir, como na música, uma diç̧ão, um timbre, uma tonalidade. Assim, ao invés dos desenvolvimentos críticos habituais, em que o que é pensado como resistência ainda vive das ilusões do sujeito, da totalidade, das promessas da razão iluminista, trata-se de explorar a resistência na forma (da linguagem, do pensamento, da arte), pois "só a forma ataca o sistema em sua própria lógica". ${ }^{13}$ Nesta perspectiva, criticar é jogar, desde que se enunciem as regras do jogo. Criticar, resistir, é uma aposta. E o que é criar?

Sabemos que diversas proposições artísticas tentaram esta façanha. Lembremos apenas, a título de exemplo, a busca da eficácia do ato simbólico no teatro da crueldade de Artaud, ao explorar a ruptura entre os signos e as coisas e ao propor um retorno para antes da representação. Não será também isto que se procura em alguns rituais musicais e festas selvagens? ${ }^{14}$ Tais exemplos provocam-nos a pensar se a vontade de fazer coincidir arte e vida não é apenas um jogo, do qual não se sai nunca, o jogo da representação, e que só podemos nos aproximar dos acontecimentos, como o horror, por exemplo, quando representados e não quando imediatamente vividos. Mas o conceito de representação é ambíguo: acentua os efeitos de presença que a tornam possível e o de ausência, que a funda; de um lado torna visível, expõe, exibe algo, como seu emprego no teatro, por exemplo; de outro, pela repetição, substitui

13 BAUDRILLARD, Jean. De um fragmento ao outro, op. cit., p. 39.

14 Cf. WARIN, François. La représentation de l'horreur, op. cit., p. 7. 
algo ausente, vicário. ${ }^{15}$ Embora um sentido remeta ao outro, como presença e ausência, prazer e desprazer. É por isso que um acontecimento grave, aquilo que é da ordem do horror, põe em questão a representação que temos do mundo, pois desestabiliza toda a compreensão que a ela propicia, já que a representação é um princípio de inteligibilidade, de razão. Mas também permite um efeito surpreendente, que esteticamente se refere à categoria do sublime: a transformação do horror em espetáculo, como vimos recentemente, de modo que o desprazer converte-se em prazer (o prazer no desprazer), mas um prazer feito de inquietante estranheza, de irrepresentável. ${ }^{16}$ Esta espécie de confusão é, na verdade, uma espécie de loucura, de negação do simbólico. Então, "se o horror é o fundo das coisas, a cultura e a linguagem [a arte] estariam aí para conter o horror", por meio da astúcia da representação, que consegue elidir a morte. ${ }^{17}$

Então duas atitudes convergentes e simultâneas comparecem: a resistência, de um lado, incide sobre as representações da cultura de consumo pondo em relevo a imagerie das sociedades democráticas que, ao privilegiarem o vivido, neutralizam o distanciamento reflexivo e perceptivo; por outro lado, valoriza o irrepresentável da experiência contemporânea, do horror. A outra atitude, a criação, tem em vista exatamente não só criticar a cultura do consumo como tentar afirmar que há qualquer coisa que pode ser concebida e que não se pode representar, não se pode ver nem fazer ver, mas que de uma maneira ou de outra é possível apresentar. Em síntese: criar é resistir. Nada tem com comunicar, antes com "nomear o informe, a ausência de forma (de representação) como índice possível do inapresentável".18 Conforme ainda observa Lyotard, situando-nos, hoje, nas fronteiras, nos limites expressivos, podemos dizer, do que pode ser apresentado, tratar-se de violentar estas fronteiras para tentar apresentar o que não pode ser apresentado. Assim, como nestas fronteiras, o pensamento desafia a sua própria finitude, a imaginação (faculdade de presentificar algo, de tornar sensível o inteligível) tenta ultrapassar os limites do possível, ou seja, quando a imaginação falha ao presentificar um objeto, devido ao desacordo com a razão, temos o sentimento do sublime, indiciando o inapresentável, o que não pode ser representado - já que não existe mais a possibilidade de projetos de domínio, ou seja, de representação do real, das coisas, pois o que existe

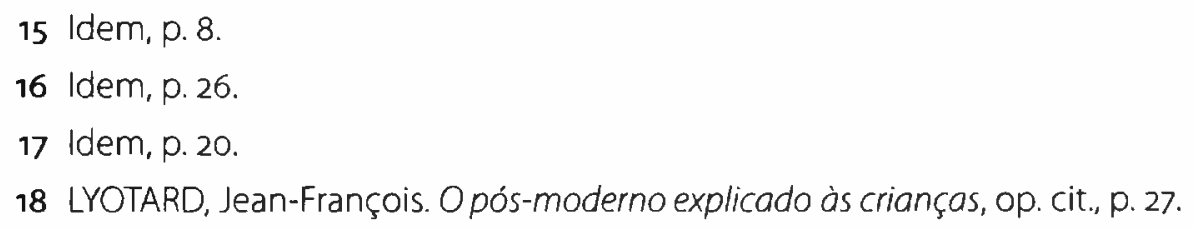


para a experiência artística é uma realidade difusa e indefinida. Este desejo ilimitado que sentimos, esse estado sublime, é o que se traduz como mescla de felicidade e infelicidade, alegria e dor ("a alegria e a dor são um tecido espesso/ uma veste para a alma divina", diz William Blake). Percebe-se então por que, ante as forças e potências que rosnam no fundo da existência, o homem se reconhece nos limites e impossibilidades, e persegue a salvação na experiência estética da finitude e da morte, do horror, sondando o abismo entre a natureza e a liberdade.

Neste momento em que as forças utópicas declinaram, paradoxalmente o que se apresenta é o signo de algo inaugural, de um recomeço a partir da estaca zero. Não sabemos signo de quê; só sabemos que estamos numa situação privilegiada. Lembrando Scott Fitzgerald, temos a sensação de estar parados, ao cair da noite, numa vasta região desértica, com um rifle vazio nas mãos e os alvos por terra, a nossos pés. Nenhum problema - um silêncio simples, cortado apenas pelo som da nossa própria respiração. ${ }^{19}$ Teríamos já nos apropriado das condições suficientes para levantar e elaborar os obstáculos modernos, principalmente de seu imperativo de produção do novo a todo custo e de crença num princípio unitário da história, da história da razão e do progresso, de modo que estaríamos agora aptos a realizar a experiência de uma vida toda feita à maneira da arte e da linguagem? Uma imagem de felicidade feita de toque, de acontecimento. Aptos a configurar as paisagens do possível e não apenas a ficar na decifração e reiteração das paisagens da memória. Apalpamos uma aragem, uma leve brisa que passa, conjurando a nossa renitente saudade do futuro com uma saudável afirmação da imanência. Livres do mito e da utopia, prosseguimos, como que retomando o fio de uma vida que julgávamos sepultada pela morte da esperança moderna e devido à persistência do terror. Em outras palavras, fazendo coexistir os signos de entusiasmo e tristeza, "avançamos num mar de surpresas e incertezas" ${ }^{20}$ Ao desencanto das promessas de uma sociedade feliz segue-se, agora, o entusiasmo moral, o entusiasmo por uma ideia, ao mesmo tempo pensamento e sentimento; ideia que está espalhada por aí, em signos contraditórios, que estão aí e que precisam ser reconhecidos e não produzidos - signos de melancolia, de tristeza, de paixão, de apatia, de dúvida, de ironia, de medo, de felicidade -, projetados em dimensão estética, isto é, na dimensão do sentimento do sublime, em que a coexistência desses signos contraditórios é manifestação do irrepresentável,

Cf. FITZGERALD, F. Scott. A derrocada (The crack-up). A derrocada e outros contos e textos autobiográficos. Trad. Álvaro Cabral. Rio de Janeiro: Civilização Brasileira, 1969, p. 47. 20 COELHO, Eduardo Prado, op. cit. 
a que somos chamados a suportar por tentativas. Suportar quer dizer que jamais esquecemos o acontecimento, que temos de ser dignos com o que acontece. Pois querer o acontecimento, o seu brilho que é o sentido, é a condição dos encontros e da transmutação. Contudo, só uma coisa é preciso: entrar no jogo, fazer a aposta. Ao invés de isso parecer um canto de esperança, alude-se aqui a outra operação: aquela que, em lugar de apostar na dissonância e nas posições alternativas - pois elas já estão previstas no sistema -, aposta, como propõe Baudrillard, na criação de "universos paralelos". ${ }^{21}$ Porque, se duvidamos da própria ideia de resistência, que carreia a de pensamento crítico, revoltado, subversivo, e, enfim, se a negatividade moderna foi absorvida e neutralizada, o que resta de todo este trabalho de limpeza é a possibilidade de mudar as regras do jogo; a proposição de uma singularidade que não resiste, mas que se constitui como um outro universo - talvez produzindo eventos, aparições, intervenções que, funcionando como ações mais ou menos regradas, exploram num espaço determinado a intersecção de tempos, linguagens e referências. Descontínuos, simultâneos, os acontecimentos assim gerados exploram as potências do instante, inscrevendo, desdobrando e reiterando signos, de cuja eficácia simbólica depende a relevância de nosso redivivo fervor.

Celso Favaretto é professor de Filosofia da Universidade de São Paulo e autor de Tropicália: alegoria alegria (Ateliê Editorial, 2007), A invenção de Hélio Oiticica (Edusp, 2003), entre outros.

21 BAUDRILLARD, Jean. De um fragmento ao outro, op. cit., p. 18. 